\title{
Simultaneous determination of two serum tumor markers in assessing malignant melanoma patients
}

\author{
Angela Sandru ${ }^{*}$, Silviu Voinea ${ }^{1}$, Eugenia Panaitescu², Madalina Bolovan ${ }^{3}$, Adina Stanciu $^{3}$, Sabin Cinca ${ }^{3}$, \\ Alexandru Blidaru'
}

From Melanoma Bridge Meeting 2014

Naples, Italy. 03-06 December 2014

\section{Background}

The incidence of cutaneous malignant melanoma (MM) continues to raise despite extensive prevention programs. If localized disease can be cured, the prognosis of metastatic melanoma is grim. Therefore, reliable methods to detect patients at risk for disease progression are sought. Field of tumor markers has captured attention because it allows the first steps toward personalized medicine. A positive tumor marker has a limited ability to correctly detect all sick people, so it was proposed to simultaneously measure several markers in order to improve their performance [1,2]. S100 and Melanoma Inhibitory Activity (MIA) are most frequently used for monitoring MM patients. Both proteins have a high specificity and their expression correlates with body tumor burden [3].

\section{Materials and methods}

Between 2009 and 2013, we determined MIA and S100 serum concentration in 120 patients with non-metastatic MM and 50 healthy donors, in order to compare diagnostic and prognostic potential of these two biomarkers. Both proteins were measured by a high sensitivity ELISA method. For S100, a threshold of $100 \mathrm{ng} / \mathrm{L}$ was accepted, as recommended by the kit manufacturer. Using the ROC curve, we estimated a MIA cut-off level of $9.4 \mathrm{ng} / \mathrm{mL}$ [4]. Patients were divided into 4 groups according to markers concentrations: both markers positive, both negative and one positive/one negative. Median, disease free and overall survival (OS) were estimated for each group.

"Department of Surgical Oncology, "Carol Davila" University of Medicine and Pharmacy; "Alexandru Trestioreanu" Oncologic Institute, Bucharest, Romania Full list of author information is available at the end of the article

\section{Results}

Survival varied depending on the number and type of markers exceeding the cut-off. Median survival decreased in this order: from S100/MIA negative group to MIA negative/S100 positive, MIA positive/S100 negative, S100/MIA positive group. It seems that a MIA value above the cut-off has a negative impact on OS greater than an increased S100 value. Two years OS was significantly higher in MIA/S100 negative group compared with MIA/S100 positive one $(81 \% / 51 \%$; $\mathrm{p}=0.05)$. Furthermore, patients with a single positive marker had a higher OS than those with both markers increased.

\section{Conclusions}

Simultaneous use of S100 and MIA increased sensitivity of identifying MM patients irrespective of clinical stage. Several tumor biomarkers determination affords selection of those produced in high volume that will be further used in patients follow-up. Measuring both MIA and S100 allows outlining of an intermediate prognosis group of patients, represented by those with a single positive marker, who have a lower risk of relapse and death than those with both positive markers.

\footnotetext{
Acknowledgment

This paper was co-financed from the European Social Fund, through the Sectorial Operational Programme Human Resources Development 20072013, project number POSDRU/159/1.5/S/138907 "Excellence in scientific interdisciplinary research, doctoral and postdoctoral, in the economic, social and medical fields -EXCELIS", coordinator The Bucharest University of Economic Studies

Authors' details

'Department of Surgical Oncology, "Carol Davila" University of Medicine and Pharmacy; "Alexandru Trestioreanu" Oncologic Institute, Bucharest, Romania. 2Department of Medical Informatics and Biostatistics, "Carol Davila" University
} 
of Medicine and Pharmacy, Bucharest, Romania. ${ }^{3}$ Department of Carcinogenesis and Molecular Biology, "Alexandru Trestioreanu" Oncologic Institute, Bucharest, Romania.

Published: 15 January 2015

\section{References}

1. Díaz-Lagares A, Alegre E, Arroyo A, González-Cao M, Zudaire ME, Viteri S, Martín-Algarra S, González A: Evaluation of multiple serum markers in advanced melanoma. Tumour Biol 2011, 32(6):1155-1161.

2. Tandler N, Mosch B, Pietzsch J: Protein and non-protein biomarkers in melanoma: a critical update. Amino Acids 2012, 43(6):2203-2230.

3. Utikal J, Schadendorf D, Ugurel S: Serologic and immunohistochemical prognostic biomarkers of cutaneous malignancies. Arch Dermatol Res 2007, 298(10):469-477.

4. Sandru A, Panaitescu E, Voinea S, Bolovan M, Stanciu A, Cinca S, Blidaru A: Prognostic Value of Melanoma Inhibitory Activity Protein in Localized Cutaneous Malignant Melanoma. J Skin Cancer 2014, Article ID 843214.

doi:10.1186/1479-5876-13-S1-P9

Cite this article as: Sandru et al: Simultaneous determination of two serum tumor markers in assessing malignant melanoma patients.

Journal of Translational Medicine 2015 13(Suppl 1):P9.

\section{Submit your next manuscript to BioMed Central} and take full advantage of:

- Convenient online submission

- Thorough peer review

- No space constraints or color figure charges

- Immediate publication on acceptance

- Inclusion in PubMed, CAS, Scopus and Google Scholar

- Research which is freely available for redistribution

Submit your manuscript at www.biomedcentral.com/submit 